\title{
A Risk-Adjusted Retrospective Data Analysis between Younger and Elderly Patients with Acute Coronary Syndromes-Long-Term Prognosis
}

\author{
Alexandre de Matos Soeiro, Alyne Pinto Borba, Aline Siqueira Bossa, Cindel Nogueira Zullino, \\ Maria Carolina Feres de Almeida Soeiro, Tatiana de Carvalho Andreucci Torres Leal, \\ Carlos V. Serrano Jr., Múcio Oliveira Tavares Jr.
}

Emergency Care Unit, Heart Institute (InCor), University of São Paulo Medical School, São Paulo, Brazil

Email: alexandre.soeiro@bol.com.br

How to cite this paper: de Matos Soeiro, A., Borba, A.P., Bossa, A.S., Zullino, C.N., de Almeida Soeiro, M.C.F., de Carvalho Andreucci Torres Leal, T., Serrano Jr., C.V. and Tavares Jr., M.O. (2016) A Risk-Adjusted Retrospective Data Analysis between Younger and Elderly Patients with Acute Coronary Syndromes-Long-Term Prognosis. Open Journal of Emergency Medicine, 4, 53-61.

http://dx.doi.org/10.4236/ojem.2016.43008

Received: July 1, 2016

Accepted: August 2, 2016

Published: August 5, 2016

Copyright $\odot 2016$ by authors and Scientific Research Publishing Inc. This work is licensed under the Creative Commons Attribution International License (CC BY 4.0).

http://creativecommons.org/licenses/by/4.0/

\begin{abstract}
Purpose: To compare the demographic data and outcomes of younger versus elderly patients with acute coronary syndromes. Methods: This was a retrospective data bank analysis study with 966 patients (268 in the younger group (less than 55 years) and 698 in the elderly group (more than 55 years)). Data were obtained about clinical characteristics, angiography, and medication used at hospital and coronary definitive treatment. The primary endpoint was all cause of in-hospital death and combined events. Comparison between groups was made by Anova and Q-square. Multivariative analysis was determined by logistic regression and was considered significative when $p<0.05$. Long-term mortality and combined events were studied using KaplanMeyer curves with median follow-up of 11.21 months. Results: The median age in the younger group was 48 years versus 69 years in the elderly group. In the younger group $26 \%$ was ST-myocardial infarction versus $18 \%$ in the elderly group. About $7 \%$ of younger patients were submitted to coronary bypass surgery and $42 \%$ to percutaneous coronary angioplasty versus $12 \%$ and $25 \%$ in elderly group, respectively. Significant difference was observed between the younger versus elderly groups in deaths $(1.5 \% \times 7.5 \%, p=0.004)$, combined events $(14.9 \% \times 26.3 \%, p=0.02)$ and killip III/IV $(3.7 \% \times 8.3 \%, p=0.04)$. Long-term mortality was $3.7 \% \times 10.2 \%, p=0.01)$. Conclusions: In patients with acute coronary syndromes age was an important predictor factor of mortality and complications. Significative differences in outcomes were observed between the two groups in-hospital and long-term follow-up.
\end{abstract}

\section{Keywords}

Young, Elder, Acute Coronary Syndrome 


\section{Introduction}

Acute Coronary Syndrome (ACS) is the main cause of hospitalization and mortality in the world. However, in Brazil, there are no accurate data about it. In this context, young patients often experience episodes of Unstable Angina (UA) and Acute Myocardial Infarction (AMI) [1]-[4]. Some changes in lifestyle, food and routine related stress could have influence on its outcome and make it happen precocis. However, most of affirmations still need scientific confirmations [1]-[4].

Studies with youngers are controversial and rare, extending only to series of cases and manly observational projects in the United States, Europe and Asia [1]-[4]. Many authors cite high prevalence of smoking, family history of early coronary arterial disease and dyslipidemia as the meaningful factors [1]-[3]. Besides that, the mortality is variable, reported between zero and $24 \%$. Regarding the basic characteristics and prognosis in ACS, an effective comparison between young and elderly has not yet been described in Brazil.

\section{Methods}

\subsection{Studied Population}

This is a retrospective and observational data bank analysis with 966 patients diagnosed with ACS (with and without ST-segment elevation) included between May 2010 and May 2013. Patients were divided into two groups: Group I $(n=268):<55$ years; Group II $(n=658):>55$ years. There were no exclusion criteria.

They were considered as having ACS all patients with established criteria by American Heart Association's last guideline [5]-[7]. ACS with positive deflection of ST-segment was defined as the presence of chest pain with persistent alteration of ST-segment $\geq 0.1 \mathrm{mV}$ in frontal planes leads and $\geq 0.2 \mathrm{mV}$ in precordial leads, at least in two contiguous leads. ACS without ST-segment elevation was defined as the presence of chest pain associated with electrocardiography alterations, rise/fall of troponin serum levels in hospitalization or, lacking these two condition, compatible clinical scenario and risk factors for AMI (severe or progressive chest pain at rest or at minimal effort). Recurrence of chest pain associated with new troponin elevation was considered as reinfarction. Major bleeding was stablished by BARC's score [8] types 3 and 4, and minor bleeding by types 1 and 2 . Stroke was considered in cases of new focal neurological deficits confirmed by cranial computerized tomography.

The following data were obtained: age, sex, presence of diabetes mellitus and systemic arterial hypertension, body mass index, smoking habit, dyslipidemia, family history for premature coronary artery disease, unstable angina and heart failure, previous coronary artery disease (AMI, percutaneous coronary intervention (PCI) or coronary bypass arterial grafting $[\mathrm{CABG}]$ ), hemoglobin, creatinine, troponin peak, left ventricular ejection fraction (LVEF) and prescribed drugs in the first 24 hours of hospitalization.

All patients were sent to follow-up after 14 days of their discharge and a new follow-up visit was scheduled 6 months later. Ischemia or catheterization tests were performed in this period according to medical staff's assessment. Monitoring was carried 
out through telephonic contact and review of medical records. In 104 cases (10.8\%), there was loss of long-term follow-up.

The project was approved by the ethics committee of the institution and an informed consent form was signed by all patients included in study.

\subsection{Statiscal Analisis}

All basal categories shown in Table 1 were considered variables in the analyses.

Comparison between groups was made by Anova and Q-square. The primary endpoint was all cause of in-hospital death and the secondary endpoint was combined events (death, non-fatal unstable angina or myocardial infarction/repeated revascularization, bleed, Killip III/IV and stroke). Multivariate analysis were determined by logistic regression and was considered significant when $p<0.05$.

Table 1. Características clínicas basais de paciente de acordo com o grupo incluído.

\begin{tabular}{|c|c|c|c|}
\hline & $\leq 55$ years & $>55$ years & \\
\hline Age (median) & $48(30-55)$ & $69(56-100)$ & $<0.01$ \\
\hline Male (\%) & $53 \%$ & $50 \%$ & 0.24 \\
\hline BMI $\left(\mathrm{kg} / \mathrm{m}^{2}\right)$ & $27.4(19.3-41.8)$ & $27.5(14.8-65)$ & 0.14 \\
\hline Diabetes Mellitus (\%) & $25 \%$ & $44 \%$ & $<0.01$ \\
\hline Hypertension (\%) & $68 \%$ & $86 \%$ & $<0.01$ \\
\hline Tabagism (\%) & $67 \%$ & $34 \%$ & $<0.01$ \\
\hline Familial history of CD (\%) & $15 \%$ & $10 \%$ & 0.01 \\
\hline Dyslipidemia (\%) & $43 \%$ & $53 \%$ & 0.003 \\
\hline Stable angina (\%) & $13 \%$ & $15 \%$ & 0.69 \\
\hline HF (\%) & $3 \%$ & $9 \%$ & 0.002 \\
\hline AMI (\%) & $27 \%$ & $42 \%$ & $<0.01$ \\
\hline Previous CABG (\%) & $10 \%$ & $19 \%$ & $<0.01$ \\
\hline Previous PCI (\%) & $21 \%$ & $28 \%$ & 0.01 \\
\hline $\mathrm{Hb}(\mathrm{g} / \mathrm{dL})$ & $14.35 \pm 1.91$ & $13.57 \pm 1.87$ & $<0.01$ \\
\hline $\mathrm{Cr}(\mathrm{mg} / \mathrm{dL})$ & $1.35 \pm 1.54$ & $1.3 \pm 1.11$ & 0.57 \\
\hline Troponin (pico) (ng/dL) & $13.70 \pm 51.58$ & $10.88 \pm 23.62$ & 0.26 \\
\hline $\operatorname{LVEF}(\%)$ & $42.73 \pm 23.46$ & $44.19 \pm 21.49$ & 0.42 \\
\hline Aspirin (\%) & $95 \%$ & $97 \%$ & 0.12 \\
\hline B-blocker (\%) & $71 \%$ & $73 \%$ & 0.72 \\
\hline Enoxaparin (\%) & $77 \%$ & $80 \%$ & 0.29 \\
\hline Clopidogrel (\%) & $59 \%$ & $53 \%$ & 0.1 \\
\hline ACE inhibitor (\%) & $60 \%$ & $60 \%$ & 0.98 \\
\hline Statin (\%) & $83 \%$ & $84 \%$ & 0.7 \\
\hline
\end{tabular}

Legend: $\mathrm{BMI}=$ body mass index; $\mathrm{CD}=$ coronary disease; $\mathrm{HF}=$ heart failure; $\mathrm{AMI}=$ acute myocardial infarction; $\mathrm{CABG}=$ coronary artery bypass grafting; $\mathrm{PCI}=$ percutaneous coronary intervention; $\mathrm{Hb}=$ hemoglobin; $\mathrm{Cr}=$ creatinine; $\mathrm{LVEF}=$ left ventricle ejection fraction; $\mathrm{ACE}$ = angiotensin-converting enzyme. 
Long-term mortality and combined events (reinfarction/reintervention and heart failure), were studied using Kaplan-Meyer curves with median follow-up of 11.21 months. Significant statistical difference was determined when $p<0.05$.

\section{Results}

The median age in the younger group (I) was 48 years versus 69 years in the elderly group (II). Significant differences were observed in the prevalence of systemic arterial hypertension ( $68 \%$ in group I $\times 86 \%$ in group II, $p<0.01)$, smoking habit $(67 \% \times 34 \%$, $p<0.01)$, family history for premature coronary artery disease $(15 \% \times 10 \%, p<0.01)$, diabetes mellitus $(25 \% \times 44 \%, p<0.01)$, dyslipidemia $(43 \% \times 53 \%, p=0.003)$, heart failure $(3 \% \times 9 \%, p=0.002)$, previous AMI $(27 \% \times 42 \%, p<0.01)$, previous CABG $(27 \% \times 42 \%, p<0.01)$, previous PCI $(21 \% \times 28 \%, p=0.01)$ and hemoglobin $(14.35 \times$ $13.57 \mathrm{mg} / \mathrm{dL}, p<0.01)$. Baseline characteristics according to each group of the studied population are shown in Table 1.

ACS with ST-segment elevation was observed in $26 \%$ of cases in the young group, while prevalence of this condition was $18 \%$ in elderly group. UA and AMI without positive deflection of ST-segment were diagnosed in $50 \% \times 51 \%$ and $24 \% \times 31 \%$, between groups I and II, respectively. About $7 \%$ of young were submitted to CABG and $42 \%$ underwent PCI. Whereas, in elderly group, it was opted to CABG in $12 \%$ and PCI in $25 \%$ of cases. Regarding the angiographic pattern, triarterial, biarterial and uniarterial occlusion were observed in $12 \% \times 25 \%, 8.5 \% \times 21 \%$ and $67 \% \times 46 \%$, respectively, when groups I and II were compared.

Multivariate analysis results comparing different in-hospital outcomes according to age are shown in Table 2. Significant differences regarding mortality $(1.5 \% \times 7.5 \%, p<$ $0.04)$, Killip III/IV $(3.7 \% \times 8.3 \%, p<0.04)$ and combined endpoints $(14.9 \% \times 26.3 \%, p$ $<0.02$ ) were observed, between young and elderly, respectively.

In long-term follow-up, combined outcomes $(47.7 \% \times 56.5 \%, p=0.04)$ and mortality $(3.7 \% \times 10.2 \%, p=0.01)$ were significantly different among group I and II. Results are displayed in Table 3 and Figure 1.

Table 2. Results of multivariate analysis of in-hospital outcomes comparing patients according with groups.

\begin{tabular}{cccc}
\hline & $\leq 55$ years & $>55$ years & $p$ \\
\hline Reinfarction & $1.5 \%$ & $1.60 \%$ & NS \\
Killip III/IV & $3.7 \%$ & $\mathbf{8 . 3 0 \%}$ & $\mathbf{0 . 0 4}$ \\
VF/VT & $1.5 \%$ & $1 \%$ & NS \\
Bleeding & $6.7 \%$ & $7.30 \%$ & NS \\
Stroke & $0.0 \%$ & $0.60 \%$ & NS \\
Mortality & $1.5 \%$ & $\mathbf{7 . 5 0 \%}$ & $\mathbf{0 . 0 0 4}$ \\
Combined events & $\mathbf{1 4 . 9 \%}$ & $\mathbf{2 6 . 3 0 \%}$ & $\mathbf{0 . 0 2}$ \\
\hline
\end{tabular}

Legend: $\mathrm{VF} / \mathrm{VT}$ = ventricular fibrilation/ventricular tachycardia; NS = non-significant. 

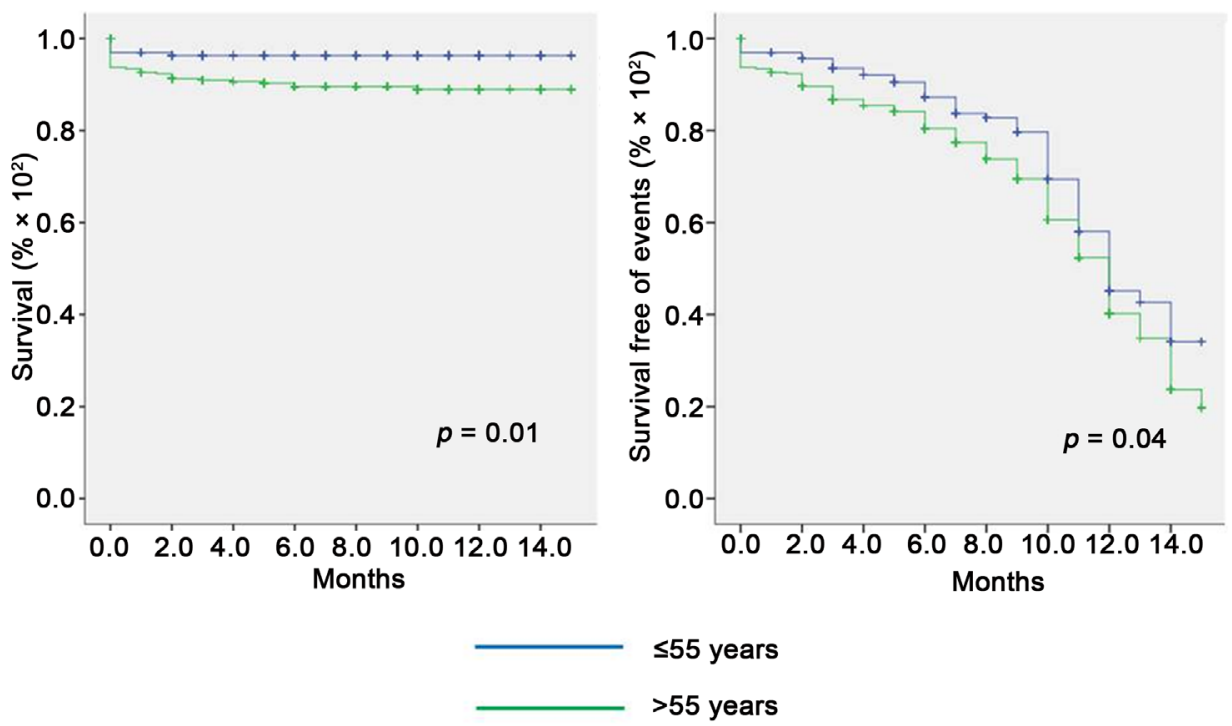

Figure 1. Survival and survival free of events in follow-up comparing young and elder patients.

Table 3. Results of long-term follow-up outcomes comparing patients according with groups.

\begin{tabular}{cccc}
\hline & $\leq 55$ years & $>55$ years & $p$ \\
\hline Reintervention & $37.3 \%$ & $36.10 \%$ & NS \\
HF & $6.7 \%$ & $10.20 \%$ & NS \\
Mortality & $3.7 \%$ & $10.20 \%$ & 0.01 \\
Combined events & $47.7 \%$ & $56.50 \%$ & 0.04 \\
\hline
\end{tabular}

Legend: $\mathrm{HF}=$ heart failure; NS = non-significant.

\section{Discussion}

First obstacle in the scientific literature regarding ACS is the definition of what age should be used as a cut-off point between young and elderly. The most accepted definition is a cut-off of 55 years like used in this study. This lack of uniformity regarding to the age definition, associated to low amount of published articles in this respect, makes comparison between different studies an arduous task. Patients under 30, 40 and 55 years represent about $0.4 \%, 10 \%$ and $20 \%$ of general population admitted for ACS, respectively [1] [2] [9]-[11]. In this study, approximately $28 \%$ of all patients treated for ACS are people with 55 years or less, being quite important in this context.

In young patients, we verified in literature an enormous number of men. This prevalence may vary between $80 \%$ to $100 \%$ in age groups from 35 to 45 years old [1]-[3] [9] [11]. In spite of our studied population also be formed mainly by man, our data show only $53 \%$. This value is lower when compared to other studies. We think that this happened because the fact that we haven't used a low age cut-off.

ACS pathophysiology in young patients could be different. Smoking, thrombophilia, vasospasm and cocaine use are more frequent on this age group [9] [10]. The incidence of thrombophilia and vasospasm can represent up to $76 \%$ of patients under 30 years 
with AMI [1]. We found only 8 cases (3\%) of ACS associated with cocaine use and 4 (1.5\%) thrombophilia cases ( 3 of them related to the presence of antiphospholipid antibody and 1 case associated with factor $\mathrm{V}$ Leiden).

Colkesen et al. [1] described that $83 \%$ of people diagnosed with AMI with ST-segment elevation under 35 years old are male and $62 \%$ have smoking history. Moreover, young patients with AMI with ST-segment elevation have family history for premature coronary disease and have levels of serum HDL-cholesterol lower when related to people of same age without coronary illness [1]-[3]. In another articles, prevalence of smoking history was described up to $81 \%$ in cases of AMI [3]. The prevalence of smoking habit in our study, as also found in others, was high (67\%) and thus was stablished as one of main risk factors in group I. Regarding family history for premature coronary artery disease, comparing patients with ACS over and under 35 years, the prevalence described of ACS is $16 \%$ versus $33 \%$, respectively [1]. The elevated index of prior AMI was an unexpected interesting finding in our analysis, yet it can be justified by the inclusion of patients at a cardiological care center.

On the other hand, in elderly population, Fach et al. [12] recently published data from STEMI Bremen registry, showing an arterial hypertension prevalence of $72.2 \%$ and diabetes mellitus prevalence of $25.1 \%$, with a progressive upward trend related to the increasing age, such as it is observed in this study. The opposite is observed regarding smoking, with an important reduction of prevalence, from $54 \%$ in patients with less than 75 years old to $5.1 \%$ in patients with less than 85 years old. About the occurrence of acute myocardial infarction, a prevalence of $12.1 \%$ is observed in patients with less than 75 years old. This prevalence in this study is far below the one observed in our population, which is probably due to the fact that only patients assisted in a cardiology tertiary hospital were included, not considering the general population.

Diabetes mellitus wasn't high in the young people and studies comparing ACS between patients with less and more than 40 years old, demonstrated a higher prevalence of diabetes in older patients [10], which can be related by the physiopathology of high levels of glycemia in atherosclerosis development. That may be required decades for a patient with diabetes to manifest coronary disease. Nevertheless, as described previously, physiopathology of ACS in this group does not shown to completely have the same typical risk factors.

Regarding the coronary illness, other authors showed that most of young population presented univascular injury (69\%), and the affected arteria is the anterior descending in $60 \%$ of the times, while only $14 \%$ has significant triple artery lesion [1]. These findings are consistent with our study, showing the important presence of single coronary lesions. We observed that only $12.5 \%$ of young patients submitted to catheterization did not show obstructive blockades. In other studies, the number of patients without any coronary lesions ( $<50 \%$ occlusion) is observed in about half of sample with acute myocardial infarction. In a Japanese study in patients with less than 40 years old, the found result was similar to our study, and only one patient of 27 (3.7\%) did not show coronary lesion [2]. 
In elderly patients, the findings related to coronary artery involvement pattern are generally opposed. Most of the studies demonstrate a progressive number and increasing of multivessel involvement according to the age group. About $17 \%$ to $57 \%$ of the patients with more than 70 years old are three arterial, with an average of 2.1 involved vessels in those patients with more than 85 years old [12]-[15].

Surgical treatment was applied only in a small number of young patients, which is similar with some descriptions previously related [1] [2]. Nevertheless, majority of patients showed in this study followed up with clinical treatment, opposite with other studies, when most of patients were submitted to percutaneous coronary intervention [1] [2]. Perhaps this difference is probably because in other studies selected only patients with acute myocardial infarction, while this study selected patients with unstable angina and with $12.5 \%$ of coronary angiography without lesions.

In elderly group, there was a low index of intervention coronary treatment, either by percutaneous coronary intervention (25\%) or myocardial revascularization surgical (12\%). These data reflects what literature has shown currently. In CRUSADE registry, only about $61 \%$ of patients with more than 65 years old and AMI without ST-segment elevation are submitted to invasive stratification and about $39 \%$ are submitted to PCI [16]. In patients with AMI and ST-segment elevation in the USA, only $40 \%$ with more than 75 years old received some form of reperfusion strategy [17]. This low rate of performing stratification procedure or reperfusion treatment is mainly due to the weakness of the patients and to the established increased risk of bleeding. Nevertheless, when properly treated, elderly patients in which were performed PCI present better long-term survival [14] [15] [18]-[20].

Real prognosis of young patients with ACS is still a controversial issue. It is possible to verify that younger patients have better prognosis in short term period than elderly patients, as shown by their high survival indices and coronary events. Shiraishi et al. [2] described in-hospital mortality in patients under 40 years next to zero [2]. Other study described a mortality of $4.9 \%$ in 30 -day period in young patients compared to $8.6 \%$ in the rest of population. After six months, the mortality was $5.5 \%$ in young patients and $9.7 \%$ in the elderly group [11]. With mean 4-year follow-up, the only prolonged monitoring study with young patients diagnosed with ACS showed $28 \%$ of need for reintervention in coronary artery disease who had expressed acute myocardial infarction [1].

In 1-year follow-up, mortality in patients over 65 years old with ACS varies from $12.2 \%$ to $61 \%$ and combined events index varies from $20.6 \%$ to $71.9 \%$ [12]-[15] [21]. We noted similar prevalence in this study, much higher than that observed in the young group, clearly inferring worse prognosis. This finding is directly related to less interventionist approach in this group, combined with all intrinsic factors of elderly patients, such as greater fragility, chronic renal failure, greater bleeding risk, etc. [15].

It is important to notify some significant limitations in this research. Among then, there is loss of follow up of reasonable number of patients throughout the study. In spite of reporting the number of young patients with thrombophilia and cocaine users, not all patients were actively questioned, what could sub estimate such conditions. This 
nevertheless is the first analysis in Brazil that evaluate short- and long-term comparative outcomes of young and elderly population diagnosed with ACS. Furthermore, such data can help prevention of risk factors and precocis detection of coronary illness mainly in young individuals.

\section{Conclusion}

In patients with coronary acute syndrome, age is considered a predictor factor of mortality and complications. Significant differences were observed in intra-hospitalar and long-term evolution.

\section{References}

[1] Colkesen, A.Y., Acil, T., Demircan, S. and Muderrisoglu, H. (2008) Coronary Lesion Type, Location, and Characteristics of Acute ST Elevation Myocardial Infarction in Young Adults under 35 Years of Age. Coronary Artery Disease, 19, 345-347. http://dx.doi.org/10.1097/MCA.0b013e3283030b3b

[2] Shiraishi, J., Kohno, Y., Yamaguchi, S., Arihara, M., Hadase, M., Hyogo, M., Yagi, T., Shima, T., Sawada, T., Tatsumi, T., Azuma, A., Matsubara, H., et al., AMI-Kyoto Multi-Center Risk Study Group (2005) Acute Myocardial Infarction in Young Japanese Adults Clinical Manifestations and In-Hospital Outcome. Circulation Journal, 69, 1454-1458. http://dx.doi.org/10.1253/circj.69.1454

[3] Kanitz, M.G., Giovannucci, S.J., Jones, J.S. and Mott, M. (1996) Myocardial Infarction in Young Adults: Risk Factors and Clinical Features. Journal of Emergency Medicine, 14, 139145. http://dx.doi.org/10.1016/0736-4679(95)02089-6

[4] Soeiro, A.M., Fernandes, F.L., Soeiro, M.C.F.A., Serrano Jr., C.V. and Oliveira Jr., M.T. (2015) Características clínicas e evolução em longo prazo de pacientes jovens com síndrome coronariana aguda no Brasil. Einstein, 13, 370-375. http://dx.doi.org/10.1590/S1679-45082015AO3381

[5] Gara, P.T.O., Kushner, F.G., Ascheim, D.D., Casey, D.E., Chung, M.K., de Lemos, J.A., et al. (2013) 2013 ACCF/AHA Guideline for the Management of ST-Elevation Myocardial Infarction. Circulation, 127, e362-e425.

[6] Steg, G., James, S.K., Atar, D., Badano, L.P., Blomstrom-Lundqvist, C., Borger, M.A., et al. (2012) ESC Guidelines for the Management of Acute Myocardial Infarction in Patients Presenting with ST-Segment Elevation-The Task Force on the Management of ST-Segment Elevation Acute Myocardial Infarction of the European Society of Cardiology (ESC). European Heart Journal, 33, 2569-2619. http://dx.doi.org/10.1093/eurheartj/ehs215

[7] Piegas, L.S., Timerman, A., Feitosa, G.S., Nicolau, J.C., Mattos, L.A.P., Andrade, M.D., et al. (2015) V Diretriz da Sociedade Brasileira de Cardiologia sobre Tratamento do Infarto Agudo do Miocárdio com Supradesnível do Segmento ST. Arquivos Brasileiros de Cardiologia, 105, 1-105. http://dx.doi.org/10.5935/abc.20150107

[8] Mehran, R., Rao, S.V., Bahht, D.L., Gibson, M., Caixeta, A., Eikelboom, J., et al. (2011) Standardized Bleeding Definitions for Cardiovascular Clinical Trials. A Consensus Report from the Bleeding Academic Research Consortium. Circulation, 123, 2736-2747. http://dx.doi.org/10.1161/CIRCULATIONAHA.110.009449

[9] Gotsman, I., Lotan, C. and Mosseri, M. (2003) Clinical Manifestation and Outcome of Acute Myocardial Infarction in Very Young Patients. Israel Medical Association Journal, 5, 633-636. 
[10] Hong, M.K., Cho, S.Y., Hong, B.K., Chang, K.J., Mo-Chung, I., Hyoung-Lee, M., et al. (1994) Acute Myocardial Infarction in the Young Adults. Yonsei Medical Journal, 35, 184189. http://dx.doi.org/10.3349/ymj.1994.35.2.184

[11] Chen, Y.L., Bhasin, A., Youssef, A.A., Wu, C.J., Yang, C.H., Hsieh, Y.K., et al. (2009) Prognostic Factors and Outcomes in Young Chinese Patients with Acute Myocardial Infarction Undergoing Primary Coronary Angioplasty. International Heart Journal, 50, 1-11. http://dx.doi.org/10.1536/ihj.50.1

[12] Fach, A., Bünger, S., Zabrocki, R., Schmucker, J., Conradi, P., Garstka, D., et al. (2015) Comparison of Outcomes of Patients with ST-Segment Elevation Myocardial Infarction Treated by Primary Percutaneous Coronary Intervention Analyzed by Age Groups $(<75,75$ to 85 , and $>85$ Years); (Results from the Bremen STEMI Registry). American Journal of Cardiology, 116, 1802-1809. http://dx.doi.org/10.1016/j.amjcard.2015.09.022

[13] Prasad, A., Stone, G.W., Aymong, E., Zimetbaum, P.J., McLaughlin, M., Mehran, R., et al. (2004) Impact of ST-Segment Resolution after Primary Angioplasty on Outcomes after Myocardial Infarction in Elderly Patients: An Analysis from the CADILLAC Trial. American Heart Journal, 147, 669-675. http://dx.doi.org/10.1016/j.ahj.2003.11.010

[14] Villanueva-Benito, I., Solla-Ruíz, I., Paredes-Galán, E., Díaz-Castro, O., Calvo-Iglesias, F.E., Baz-Alonso, J.A., et al. (2011) Prognostic Impact of Interventional Approach in Non-ST Segment Elevation Acute Coronary Syndrome in Very Elderly Patients. Revista Española de Cardiología, 64, 853-861. http://dx.doi.org/10.1016/j.recesp.2011.04.022

[15] Shah, P., Najafi, A.H., Panza, J.A. and Cooper, H.A. (2009) Outcomes and Quality of Life in Patients $\geq 85$ Years of Age with ST-Elevation Myocardial Infarction. American Journal of Cardiology, 103, 170-174. http://dx.doi.org/10.1016/j.amjcard.2008.08.051

[16] Lopes, R.D., Subherwal, S., Holmes, D.N., Thomas, L., Wang, T.Y., Rao, S.V., et al. (2012) The Association of In-Hospital Major Bleeding with Short-, Intermediate-, and Long-Term Mortality among Older Patients with Non-ST-Segment Elevation Myocardial Infarction. European Heart Journal, 33, 2044-2053. http://dx.doi.org/10.1093/eurheartj/ehs012

[17] Mazhari, R. and Kapur, N. (2014) Increased Risk and Increased Reward in Coronary Intervention in Older Patients with Acute Coronary Syndrome. Heart, 100, 1483-1484. http://dx.doi.org/10.1136/heartjnl-2014-306134

[18] Angeli, F., Verdecchia, P., Savonitto, S., Morici, N., De Servi, S. and Cavallini, C. (2014) Early Invasive versus Selectively Invasive Strategy in Patients with Non-ST-Segment Elevation Acute Coronary Syndrome: Impact of Age. Catheterization and Cardiovascular Interventions, 83, 686-701. http://dx.doi.org/10.1002/ccd.25307

[19] Sandhu, K. and Nadar, S.K. (2015) Percutaneous Coronary Intervention in the Elderly. International Journal of Cardiology, 199, 342-355. http://dx.doi.org/10.1016/j.ijcard.2015.05.188

[20] Sanchis, J., Bonanad, C., Ruiz, V., Fernández, J., García-Blas, S., Mainar, L., et al. (2014) Frailty and Other Geriatric Conditions for Risk Stratification of Older Patients with Acute Coronary Syndrome. American Heart Journal, 168, 784-791. http://dx.doi.org/10.1016/j.ahj.2014.07.022

[21] Angeli, F., Cavallini, C., Verdecchia, P., Morici, N., Del Pinto, M., Petronio, A.S., et al. (2015) A Risk Score for Predicting 1-Year Mortality in Patients $\geq 75$ Years of Age Presenting with Non-ST-Elevation Acute Coronary Syndrome. American Journal of Cardiology, 116, 208-213. http://dx.doi.org/10.1016/j.amjcard.2015.04.015 
Submit or recommend next manuscript to SCIRP and we will provide best service for you:

Accepting pre-submission inquiries through Email, Facebook, LinkedIn, Twitter, etc. A wide selection of journals (inclusive of 9 subjects, more than 200 journals)

Providing 24-hour high-quality service

User-friendly online submission system

Fair and swift peer-review system

Efficient typesetting and proofreading procedure

Display of the result of downloads and visits, as well as the number of cited articles

Maximum dissemination of your research work

Submit your manuscript at: http://papersubmission.scirp.org/ 